\title{
Empirical Study on the Chinese Culture Transmission and Effects
}

\begin{abstract}
ZHANG Jie
China Youth University of Political Studies, Beijing, China

In the new historical period, China needs to show the nation's values and national spirit. With the advent of the era of globalization, the strength of a country is not only reflected in the economy, cultural factors will play an increasingly important role in the social development process in 21 th century. The impact of cultural soft power and communication is essential for a country to power. In the process of going to the world, and in line with the international community, the Chinese culture will inevitably have a dialogue with the West. China will catch up with the world's advanced level. We must pay attention to enhance the competitiveness of culture and penetration. The paper analyzes the historical and present Chinese culture oversea transmission and the effects of the transmissions. The paper has three parts - the first part is the history of Chinese culture transmission; the second part is the present Chinese transmission; and the third part is the effects of Chinese culture transmission.

Keywords: Chinese culture, transmission, effects
\end{abstract}

\section{Introduction}

Nowadays, culture has been absolutely considered a power of productivity. The impact of cultural soft power and communication is essential for a country to power. More and more countries are paying more attention to the transmission of culture. In the whole world, every country takes opportunities to get the culture known, understood, and accepted. China is a country with a long history, even with a long history of culture transmission. At the new era of history, China has been aware the importance of culture transmission. From the end of last century, both Chinese government and non-governmental groups have done many activities on the Chinese culture, and get the world to be familiar with Chinese culture. The paper is to make some research about Chinese culture, and the effects on the transmission of the Chinese culture. With some questionnaires as the base of the research, the paper is to analyze the relations between the relevant items.

\section{Understanding the Definition of Culture}

What is culture? Culture is an integral part of every society. It is a learned pattern of behavior and ways in which a person lives his or her life. Culture is essential for the existence of a society, because it binds people together. In the explicit sense of the term, culture constitutes the music, food, arts, and literature of a society. However, these are only the products of culture followed by the society and cannot be defined as culture.

According to English Anthropologist Edward B Taylor, culture is that complex whole which includes

ZHANG Jie, associate professor, master, Department of Foreign Language and Literature, China Youth University of Political Studies. 
knowledge, belief, art, law, morals, custom, and any other capabilities and habits acquired by man as a member of society. Culture is something that a person learns from his family and surroundings, and is not ingrained in him from birth. It does not have any biological connection because even if a person is brought up in a culture different from that in which he was born, he imbibes the culture of the society where he grows up. It is also not a hidden fact that some people feel the need to follow the beliefs and traditions of their own culture, even though they might be not subscribing to certain ideologies within. ${ }^{1}$

\section{The Synopsis of Chinese Culture Transmission}

\section{The History of Chinese Culture Transmission to the World}

A country's culture development connects with the culture transmission from a long run. In the 5,000 years, Chinese has formed the core culture based on the Confucius culture.

The Chinese transmission began with the Han Dynasty, which is famous for the "The silk route". Tang dynasty is at peak of Chinese culture transmission. Foreign mission came eagerly to Chang'an. Thousands of oversea students came to study culture in the imperial college to receive the authentic Chinese education (WU, 2008). Chinese cultures at time greatly affected the Asia, and formed the culture circle based on Chinese culture. The Chinese characters and Confucius are followed in Asian countries, especially in Japan and Korean peninsula.

Another peak of Chinese culture transmission is at the time of Qing Dynasty. At that time the Chinese culture transmission is beyond Asia. It is around the world. The missionaries took the part of culture transmission. They translated many Chinese classic books, and introduced Chinese history, political system, literature, and art. All the culture activities infused oriental element for the renaissance.

Some important figures played vital role in the history of Chinese culture transmission. They are the ZHANG Qian, JIAN Zhen, ZHENG He, to name just a few.

In the past 30 years, with the development of Chinese economic changes, with the availability of the global cooperation, Chinese are more confident in the Chinese culture transmission. The "China fever" and "Mandarin fever" are long lasting (HE, 2013).

\section{The Present Situation of Chinese Culture Transmission}

The 17th plenary session in China proposed "to enforce the influences and inspiration of Chinese culture, and to keep the varieties of cultures". According to the Xinhua news, during the "15th" the export of Chinese core culture products rose to $\$ 1,116.7$ million from $\$ 78.9$ million, with the average of $8.1 \%$; the export of culture rose to 30.1 million with the average of $20 \%$ (LIU, 2012).

The first Confucius College started on September 21, 2004 in Seoul, Korea. The first Confucius television station started to broadcast on December 17, 2008. Till now, there are over 700 Confucius Colleges around the world, among them 70 are in the United States. The Confucius College is an effective way for Chinese culture transmission.

And the Confucius Colleges held more than 7,000 culture activities, with more than 200 million persons taking part in. In the late few years, some culture year were held around the world, centered on the "Old China", "Colorful China", and "Modern China".

\footnotetext{
1 See

http://wenku.baidu.com/link?url=UtDJxkEB68LVWQQ0Tt09GozEkJ_Ziujd5ufZc8AUiZ-ziQcY8sbGFPVzT8EzCwIBDMfYxnp LGLbJaLuZ5BWG9Tjb1WLDXt2ErQxf37M-dJK.
} 
Many scholars wrote papers to explain the development of present Chinese culture transmission. In the article The Study of International Transmission of the Chinese Traditional Cultures, Jin talked about three main ways of Chinese culture transmission. They are literature channel with the Confucius classic works, which are the core of Chinese traditional culture, the activity channel, which combines the learning of Chinese culture in activities (JIN, 2010).

There are different transmissions for the Chinese culture. The traditional classics, the modern works, representatives of MO yan's, JIA Ping-wo's works are the best Chinese literature transmission to abroad.

In the modern time the most convenient and quick transmission is the movie series. Legend of LI Xiao Long has been screened for more than 60 countries. And the new Three Kingdom got the profit over 100 million. ${ }^{2}$

\section{Empirical Study on the Chinese Culture Effects}

The paper is to analyze the effects of Chinese culture transmission, so the questionnaire is important for the analysis. The questionnaires are from three universities, located in Beijing and Jilin - the northeast of China. Totally there are over 100 hundred valid questionnaires. The following is the relevant items of the questions concerned.

There are three parts in the questionnaire. The first par is about the simple facts; the second part is about the habitual facts of Chinese study; and the last part is about knowledge about Chinese culture. In the first part the gender, the age, education, the time for study Chinese every day, the time for studying Chinese, and satisfaction of Chinese study are concerned. In the second part, the situation of Chinese study, the communication partner of Chinese language, the way of Chinese communication, and the reasons why Chinese was used to with communication are concerned. In the third part, it is all mainly about the knowledge of Chinese culture. Here is the questionnaire (see Appendix).

First: the age and with whom they talk about Chinese culture

Table 1

The Relation Between Age and With Whom They Talk About Chinese Culture

\begin{tabular}{|c|c|c|c|c|c|c|c|c|}
\hline & & \multicolumn{6}{|c|}{ With whom you talk about Chinese culture } & \multirow{2}{*}{ Total } \\
\hline & & Classmates & Relative & Net friends & Teachers & Pals & Others & \\
\hline \multirow{4}{*}{ Age } & \multirow{2}{*}{25 and below } & 67 & 2 & 2 & 20 & 3 & 4 & 98 \\
\hline & & $68.4 \%$ & $2.0 \%$ & $2.0 \%$ & $20.4 \%$ & $3.1 \%$ & $4.1 \%$ & $100.0 \%$ \\
\hline & \multirow{2}{*}{25 and above } & 16 & 0 & 1 & 4 & 6 & 0 & 27 \\
\hline & & $59.3 \%$ & $.0 \%$ & $3.7 \%$ & $14.8 \%$ & $22.2 \%$ & $.0 \%$ & $100.0 \%$ \\
\hline \multirow{2}{*}{ Total } & & 83 & 2 & 3 & 24 & 9 & 4 & 125 \\
\hline & & $66.4 \%$ & $1.6 \%$ & $2.4 \%$ & $19.2 \%$ & $7.2 \%$ & $3.2 \%$ & $100.0 \%$ \\
\hline
\end{tabular}

Table 2

Chi-Square Test

\begin{tabular}{llll}
\hline & Value & df & Sig. \\
\hline Pearson Chi-Square test & $13.300^{\mathrm{a}}$ & 5 & .021 \\
likelihood ratio & 12.170 & 5 & .033 \\
The linear and linear combination & 1.336 & 1 & .248 \\
N in the valid & 125 & & \\
\hline
\end{tabular}

${ }^{2}$ CAI, Z. G. (2014). Legend of LI Xiao Long. “Television Researches” No. 2 (Total: 291). 
Showed with the table: $(\mathrm{N}=125, \mathrm{df}=5, \mathrm{P}=0.21<0.05)$, the age has obvious relation with whom you talk about Chinese culture. The younger they are, the more they are likely to talk about Chinese culture with their classmates.

Second: the gender and where their interests are from

Table 3

Gender and Interests Relation

\begin{tabular}{|c|c|c|c|c|c|c|c|c|c|}
\hline & & \multicolumn{7}{|c|}{ Interests about Chinese culture from } & \multirow{2}{*}{ Total } \\
\hline & & TV series & Sports & Food & Traditional & Curiosity & Recommended by others & Others & \\
\hline \multirow{4}{*}{ Gender } & \multirow{2}{*}{ Male } & 9 & 5 & 4 & 11 & 11 & 8 & 2 & 50 \\
\hline & & $18.0 \%$ & $10.0 \%$ & $8.0 \%$ & $22.0 \%$ & $22.0 \%$ & $16.0 \%$ & $4.0 \%$ & $100.0 \%$ \\
\hline & \multirow{2}{*}{ Female } & 12 & 0 & 13 & 22 & 12 & 5 & 0 & 64 \\
\hline & & $18.8 \%$ & $.0 \%$ & $20.3 \%$ & $34.4 \%$ & $18.8 \%$ & $7.8 \%$ & $.0 \%$ & $100.0 \%$ \\
\hline \multirow{2}{*}{ Total } & & 21 & 5 & 17 & 33 & 23 & 13 & 2 & 114 \\
\hline & & $18.4 \%$ & $4.4 \%$ & $14.9 \%$ & $28.9 \%$ & $20.2 \%$ & $11.4 \%$ & $1.8 \%$ & $100.0 \%$ \\
\hline
\end{tabular}

Table 4

Chi-Square Test

\begin{tabular}{llll}
\hline & Value & df & Sig. \\
\hline Pearson Chi-Square test & $15.104^{\mathrm{a}}$ & 6 & .019 \\
likelihood ratio & 17.907 & 6 & .006 \\
The linear and linear combination & .706 & 1 & .401 \\
N in the valid & 114 & & \\
\hline
\end{tabular}

Showed with the table: $(\mathrm{N}=114, \mathrm{df}=6, \mathrm{P}=0.019<0.05)$. So gender and that where the interest is from exits obvious related. Males are more interested in the IV series and sports, while females are more interested in traditional things, curiosity, and the TV series.

Third: gender and the culture you want to know mostly

Table 5

The Relation Between the Gender and the Kind of Culture They Want to Know

\begin{tabular}{|c|c|c|c|c|c|c|c|c|c|}
\hline & & \multicolumn{7}{|c|}{ The Culture you want to know mostly } & \multirow[b]{2}{*}{ Total } \\
\hline & & $\begin{array}{l}\text { Movie and } \\
\text { television }\end{array}$ & $\begin{array}{l}\text { Literature } \\
\text { and art }\end{array}$ & Diet & $\begin{array}{l}\text { Chinese } \\
\text { marital art }\end{array}$ & $\begin{array}{l}\text { Handcraft } \\
\text { art }\end{array}$ & $\begin{array}{l}\text { Chinese minority dressing } \\
\text { and ornaments }\end{array}$ & Other & \\
\hline \multirow{4}{*}{ Gender } & \multirow{2}{*}{ Male } & 3 & 12 & 4 & 2 & 1 & 1 & 1 & 24 \\
\hline & & $12.5 \%$ & $50.0 \%$ & $16.7 \%$ & $8.3 \%$ & $4.2 \%$ & $4.2 \%$ & $4.2 \%$ & $100.0 \%$ \\
\hline & \multirow{2}{*}{ Female } & 10 & 5 & 6 & 8 & 4 & 6 & 4 & 43 \\
\hline & & $23.3 \%$ & $11.6 \%$ & $14.0 \%$ & $18.6 \%$ & $9.3 \%$ & $14.0 \%$ & $9.3 \%$ & $100.0 \%$ \\
\hline \multirow{2}{*}{ Total } & & 13 & 17 & 10 & 10 & 5 & 7 & 5 & 67 \\
\hline & & $19.4 \%$ & $25.4 \%$ & $14.9 \%$ & $14.9 \%$ & $7.5 \%$ & $10.4 \%$ & $7.5 \%$ & $100.0 \%$ \\
\hline
\end{tabular}

Table 6

Chi-Square Test

\begin{tabular}{llll}
\hline & Value & df & Sig. \\
Pearson Chi-Square test & $13.522^{\mathrm{a}}$ & 6 & .035 \\
likelihood ratio & 13.559 & 6 & .035 \\
The linear and linear combination & 3.267 & 1 & .071 \\
$\mathrm{~N}$ in the valid & 67 & & \\
\hline
\end{tabular}


Showed with the table: $(\mathrm{N}=67, \mathrm{df}=6, \mathrm{P}=0.035<0.05)$. So the gender and the mostly want to know items of culture are obvious related. Males more wanted to know the literature and arts, while females more wanted to know the TV and television.

\section{Conclusion}

With the understanding of culture and the transmission of Chinese culture, the main part of the paper analyzed the effects of Chinese culture transmission from different angles. By the scientific analysis, the result is that the youngsters are more likely to talk about Chinese culture and the different genders have different inclinations to Chinese culture. As in the questionnaire mentioned some other items related, the result is that the great wall is the number one place for the foreign students want to visit; Spring Festival is the most anticipated holiday; the most charming cities are both Beijing and Shanghai; and more students know about China through the internet, through the international activities, and through communication. Because the pages limitation and the need of further researches in the late study, anyway with the questionnaire the facts show that more and more Chinese cultures have been and are being transmitted worldwide and accepted by the people in the world.

\section{References}

HE, M. X. (2013). How the press serves to strengthen the culture composition. Beijing: China Publishing House.

HAN, X. Y. (2014). What is culture? Retrieved http://wenku.baidu.com/link?url=UtDJxkEB68LVWQQ0Tt09GozEkJ_Ziujd5ufZc8AUiZ-ziQcY8sbGFPVzT8EzCwIBDMf YxnpLGLbJaLuZ5BWG9Tjb1WLDXt2ErQxf37M-dJK

ZHAO, L. (2014). The declines with the inbound numbers and degree of satisfaction in 2013. Retrieved from $\mathrm{http}: / /$ www.cntour2.com/viewnews/2014/10/21/7GkgFs8tSIcpeAk5q7wP0.shtml

JIN, Z. R. (2010, November). The Chinese culture international transmission. Guangming Daily.

LIU, Y. Z. (2012). How the Chinese culture was introduced to the world. [EB] XinHuanet.

WU, B. (2008, August 21). The historical law for Chinese culture transmission. Guangming Daily Beijing.

ZHANG, X. P. (2014). The Chinese culture transmission-The sinology and it's dialogue with Chinese ancient civilization. International Communication, 2, 103.

Appendix: Questionnaire on the Chinese Culture Transmission Abroad

Part One
1-1、Gender
(1) male
(2) female
1-2、Age
(1) 20 - (2) $20 \sim 25$ (3) $26 \sim 30$ (4) $31 \sim 35$ (5) $35+$

1-2、 Education (1) junior (2) senior or technical high school (3) college (4) undergraduate course (5) graduate

1-4、Time for study everyday (1) $-2 \mathrm{~h}$ (2) $3 \sim 5 \mathrm{~h}$ (3) $6 \sim 8 \mathrm{~h}$ (4) $9 \sim 11 \mathrm{~h}$ (5) $12 \mathrm{~h}+$

1-5. How long have your studied Chinese (1) $-1 \mathrm{Y}$ (2) $2 \sim 3 \mathrm{Y}$ (3) $4 \sim 5 \mathrm{Y}$ (4) $6 \sim 7 \mathrm{Y}$ (5) $8 \mathrm{Y}+$

1-6、Are you satisfied with your Chinese study (1) not at all (2) not (3) ok (4) satisfied (5) quite satisfied

Part Two

2-1、Your Chinese study or work situation is inclined to (1) by yourself (2) by yourself, but occasionally with others (3) ok with yourself or with others (4) mostly with others (5) only with others

2-2、With whom you talk about Chinese culture, 1 2 (choose two options according to its possibility) (1) classmates (2) folks (3) online friends (4) teachers (5) interest pals (6) others

2-3、The persons you often connect by qq or other message devices are, 1 2 (choose two options according to its possibility) (1) native friends (2) Chinese friends (3) folks (4) online friends (5) teachers (6) interest pals (7) strangers (8) others, 
2-4、Reasons you talk about Chinese culture with others, 1 2 (choose two options according to its possibility) (1) for work or career (2) others' influence (3) the blood or marital relationship (4) common interests (5) for fun (6) others,

\section{Part Three}

3-1、Your Knowledge about Confucius is from (1) TV, net, media (2) extensive reading (3) school (4) folks (5) native country (6) China (7) others,

3-2、Your Knowledge about Mencius is from (1) TV, net, media (2) extensive reading (3) school (4) folks (5) native country (6) China (7) others,

3-3、Your Knowledge about Laocius is from (1) TV, net, media (2) extensive reading (3) school (4) folks (5) native country (6) China (7) others,

3-4、Your Knowledge about Mao Zedong is from (1) TV, net, media (2) extensive reading (3) school (4) folks (5) native country (6) China (7) others,

3-5、Your Knowledge about Deng Xiaoping is from (1) TV, net, media (2) extensive reading (3) school (4) folks (5) native country (6) China (7) others,

3-6、Your Knowledge about Yao Ming is from (1) TV, net, media (2) extensive reading (3) school (4) folks (5) native country (6) China (7) others,

3-7、Your Knowledge about china is from (1) TV, net, media (2) extensive reading (3) school (4) folks (5) native country (6) China (7) others,

3-8、The sequence of Chinese sports in your knowledge is (1) Pingpang , (2) gymnasium , (3) diving , (4) others,

3-9、The sequence of Chinese diet in your knowledge is (1) Jiaozi (2) noodles , (3) rice (4) others,

3-10、The sequence of Chinese festivals in your knowledge is (1) Spring festival (2) Mid-autumn , (3) National day , (4) others,

3-11、The sequence of Chinese scenery in your knowledge is (1) Terra cotta warriors (2) Forbidden city

(3) Great Wall (4) Potala palace (5) Summer Palace (6) others

3-12、Interests about Chinese culture from (1) TV series (2) sports (3) food (4) traditional (5) curiosity (6) others

3-13、The city(ies) you want to go in China (1) Beijing (2) Shanghai (3) Xian (4) Tibetan (5) Lijiang (6) Harbin (7) others

3-14、 The Culture you want to know mostly (1) movie and television (2) literature and art (3) diet (4) Chinese marital art (5) handcraft art (6) Chinese minority dressing and ornaments (7) others 